\title{
Molecular cell pathology of pollutant-induced liver injury in flatfish: use of fluorescent probes
}

\author{
Michael N. Moore \\ Plymouth Marine Laboratory (NERC), Citadel Hill, Plymouth, Devon PL1 2PB, United Kingdom
}

\begin{abstract}
This study was conducted to test whether live cells from the liver of fish could be used to detect early changes that are indicative of pollutant-induced liver damage. During the Bremerhaven Workshop, low molecular weight fluorescent probes were inserted into isolated hepatocytes from dab Limanda limanda caught at each of 5 sites along a transect in the North Sea, ranging from the Elbe plume to the edge of the Dogger Bank. These included bioprobes for endoplasmic reticulum (ER), cytochrome P-450 associated 7-ethoxyresorufin-O-deethylase (EROD), oxyradicals, reduced glutathione (GSH) and microtubules (MT). Endocytosis of Texas Red-albumin was used as an integrated indicator of hepatocyte performance. Findings showed increases in ER associated fluorescence, EROD and oxyradical generation, with a marked decrease in endocytosis in hepatocytes from fish caught at the more contaminated inshore sites. These results indicate that fish from the contaminated sites were impacted by organic xenobiotics as indicated by increased activity of the biotransformation system, increased radical production and cell injury.
\end{abstract}

\section{INTRODUCTION}

Various types of flatfish are increasingly being used as sentinels for the detection of reduced environmental quality (Spies et al. 1988, Hinton \& Laurén 1990). Flatfish live in close association with the sediments, which are often the main repository for toxic chemical pollutants, and hence, might be expected to display signs of distress or damage if so exposed. Unfortunately, flatfish are not ideal sentinel animals as they show migratory patterns (Rijnsdorp et al. 1992) that make interpretation of observed effects more difficult than in the case of many sedimentary benthic invertebrates, such as bivalve molluscs (Moore 1990). Nonetheless, it should still be possible to use rapid molecular and cellular responses to toxic chemical exposure as markers of biological damage, although longer term pathological changes are obviously more open to interpretation (Moore \& Simpson 1992).

The rationale for the use of flatfish as environmental sentinels is further reinforced by the fact that the main habitats for both juvenile and adult forms of many fish species are estuaries and coastal zones. However, it is these very areas which are likely to be affected by human activities such as urbanization and industrialization. It is conceivable, therefore, that human activities resulting in the contamination of sediments in estuaries and coastal zones can result in the loss of the living resource through chronic toxicity and impairment of reproductive capability or early deaths of both adult and larval fish (see review by Hinton \& Laurén 1990). Human health may also be at risk through consumption of contaminated fish products.

The aim of this study was to use fluorescent molecular probes coupled with image analysis and laser confocal microscopy to obtain a multiparameter picture of molecular and cellular reactions to toxic pollutants in liver cells of the flatfish dab Limanda limanda from the North Sea (De Basio et al. 1987, Lohse 1990). The approach is based on the identification of early onset of molecular and cellular changes or biomarkers of the processes of cell injury and attempts to link these to higher levels of biological damage. Liver cells (hepatocytes) are the focus of the study as the liver is an integrator of many functions including detoxication/ activation of toxic chemicals, digestion and storage, 
excretion and, in females, synthesis of the egg yolk protein. There is also a considerable body of literature on pollutant chemical impact on the cellular pathology of fish liver (see review by Hinton \& Laurén 1990).

Specifically, the approach involved the use of low molecular weight fluorescent probes inserted into live hepatocytes isolated from the livers of visibly diseasefree fish. These probes were selected for their relevance to key processes known or believed to be important in chemically induced cell injury, such as radical production, or as indicators of reactions to chemical exposure. Such disturbance of the intricate network of molecular machinery, which must function with a high degree of co-ordination to maintain the processes of life, can result in functional failure within parts of the cell often leading to a cascade of injurious effects culminating in pathological change, such as cell death or tumour formation. Processes selected for study include oxygen radical (superoxide) generation, proliferation of endoplasmic reticulum (ER), 7-ethoxyresorufin-Odeethylase (EROD) activity, endocytosis, as well as changes in the amount of reduced glutathione and microtubules (Teresaki et al. 1984, 1986, Rice et al. 1986, Hiratsuku \& Kato 1987, White 1988, Winston et al. 1991). The cellular specificities of the fluorescent probes had been previously characterized by these authors.

\section{MATERIALS AND METHODS}

Sampling procedure. Liver cells were obtained from visibly disease-free female fish caught at 5 stations along a transect in the North Sea stretching from the Elbe plume in the German Bight to the eastern end of the Dogger Bank.

Samples of flatfish dab Limanda limanda were caught in short trawls (<30 min fishing time) from Stns $3,5,6,7 \& 9$ along a transect in the North Sea from the Elbe plume (Stn 3) to the eastern edge of the Dogger Bank (Stn 9). Stn 3 was the most heavily contaminated, while Stn 7 was the least contaminated (see Cofino et al. 1992). Fish were sexed, measured and placed in flow-through tanks for transportation back to the laboratory. Only one site was sampled on a fishing trip, and the fish were held in the flow-through tanks for $(6 \mathrm{~h})$ on return to harbour before being sampled.

Ten female fish (17 to $25 \mathrm{~cm}$ body length) were randomly selected from the samples caught at each of 5 stations in the southern North Sea. Only fish which were deemed to be disease-free on visual inspection of the exterior and viscera were used in this study as it is conceivable that higher level reactions to disease will interfere with liver function and, hence, make interpretation of any observed deleterious effects difficult.
Disaggregation procedure. Disaggregation of the liver was carried out as described by Lowe et al. (1992) as follows. Approximately half of each liver was then sliced into small pieces and placed into Earles $\mathrm{Ca}^{2+} / \mathrm{Mg}^{2+}$ free balanced salt solution to which had been added EDTA and $\mathrm{NaCl}$ and incubated with continuous agitation. Enzymic disaggregation was then carried out in an amended Hanks balanced salt solution containing $\mathrm{NaCl}, \mathrm{NaHCO}_{3}, \mathrm{HEPES}, \mathrm{HCl}$, and collagenase and lipase. The resulting cells were then washed in the above amended Hanks solution minus enzymes and stored at $10^{\circ} \mathrm{C}$ in an amended Eagles Minimum Essential Medium containing non-essential amino acids, L-glutamine and bovine serum albumin. The disaggregation procedure used in this study resulted in typical cell viability in excess of $95 \%$, using eosin $\mathrm{Y}$ as an indicator, and a yield in the order of $10^{6}$ cells $\mathrm{ml}^{-1}$.

Fluorescent probe treatments. Isolated hepatocytes (20 $\mu \mathrm{l}$ of cell suspension) were allowed to attach to cleaned glass slides for $15 \mathrm{~min}$ at $20^{\circ} \mathrm{C}$ prior to exposure to the probe solutions. Fluorescent molecular probes used in this study included 3,3'-dihexyloxacarbocyanine iodide $\left(\mathrm{DiOC}_{6}(3)\right)$ and rhodamine $\mathrm{B}$ hexylester (R6) for endoplasmic reticulum (ER), dihydrorhodamine 123 (DiHR123) for superoxide radicals, 7-ethoxyresorufin for EROD, monochlorobimane for GSH, NBD-colcemid for microtubules and Texas Red conjugated albumin for endocytosis (Rice et al. 1986, Teresaki et al. 1986, Hiratsuku \& Kato 1987, White 1988, Winston et al. 1991). With the exception of the albumin, all probes were prepared as stock solutions in DMSO and used at a dilution of $10^{-4}$ in culture medium (amended Hanks balanced salt solution as described in previous section). Incubation times were as follows: $\mathrm{DiOC}_{6}(3), 10 \mathrm{~min}, 250 \mathrm{ng} \mathrm{ml}^{-1}$; $\mathrm{R} 6,10 \mathrm{~min}, 250 \mathrm{ng} \mathrm{ml}^{-1}$; 7-ethoxyresorufin, $10 \mathrm{~min}, 2.4 \mu \mathrm{g} \mathrm{ml}^{-1}$; dihydrorhodamine $123,15 \mathrm{~min}, 43 \mu \mathrm{M}$; monochlorobimane, $10 \mathrm{~min}$, $2.3 \mu \mathrm{g} \mathrm{ml}^{-1}$; NBD-colcemid, $10 \mathrm{~min}, 270 \mathrm{ng} \mathrm{ml}^{-1}$. The reaction for oxyradicals was quenched after $10 \mathrm{~min}$ by the addition of $\mathrm{N}$-t-butyl- $\alpha$-phenylnitrone (PBN) to give a final concentration of $100 \mathrm{mM}$ (Winston et al. 1991). Texas Red albumin was dissolved directly in culture medium to give a final concentration of $40 \mu \mathrm{g} \mathrm{ml}^{-1}$ and cells were incubated in this medium for 60 min at $20^{\circ} \mathrm{C}$. This medium containing the fluorescent probe was then removed and replaced with culture medium.

All incubations were performed in the dark in a humidity chamber (sealed polythene container, $30 \times$ $30 \times 15 \mathrm{~cm}$ ) at $20^{\circ} \mathrm{C}$. Cell preparations were coverslipped and sealed with medicinal liquid paraffin. An FITC filter-block was used for visualising ER, oxyradical generation and microtubules; a blue-violet filter block was used for GSH; a rhodamine block was used 
for EROD; and a Texas Red block was used for endocytosis. An additional probe was used to test for ER; this was rhodamine B hexylester (R6), which requires a rhodamine block for visualization (Haugland 1989, M. Teresaki unpubl.).

Attached hepatocytes were fix-killed in Baker's formol calcium for 15 min at $4{ }^{\circ} \mathrm{C}$, rinsed in culture medium and exposed to the probe solutions as indicated for the live cells above.

Analysis of cell images. A laserscan confocal microscope (SARASTRO/Molecular Dynamics) with Silicon Graphics imaging capabilities was used in the detailed study of the localization of the fluorescent bioprobes in the liver cells. For routine measurements, epifluorescence images of liver cells ( $>100$ cells sample ${ }^{-1}$ ) were captured on high resolution video tape (Sony Pro X) using a Sony Colour Video Camera coupled to a Zeiss Axiomat fluorescence microscope. A random subset of 20 images were scored against a set of prepared micrographs of fluorescence for the appropriate probe (grey level range 0 to $250 ; 13$ micrographs in total covering the grey level range in regular increments); the fluorescent cells on the prepared micrographs having been previously calibrated with a Molecular Dynamics Sarastro Confocal Laser Scanning Microscope interfaced to a Silicon Graphics computer.

There was no significant background fluorescence from the probe solutions as they only fluoresce when bound within the cell. The exception was Texas Red albumin but the medium containing this probe was removed before any images were taken. The isolated hepatocytes did not show any significant autofluorescence under any of the epifluorescence regimes.

Twenty cells (diameter $12 \pm 2 \mu \mathrm{m}$ ) were measured per liver sample and the Mann-Whitney $U$-test was used for statistical analysis of the data.

\section{RESULTS}

\section{Cellular localizations of probes}

The results showed that the 2 probes used to detect endoplasmic reticulum in the hepatocytes both had the same type of distribution in a tubular and lamellar network as demonstrated using confocal imaging (Fig. 1A, $B$ ). This finding supports the premise that the probes are probably localising in the ER and not in other intracellular structures. The fluorescent probes $\mathrm{DiOC}_{6}(3)$ and R6 used in this study are believed to be reasonably specific for endoplasmic reticulum, although there may also be some mitochondrial staining with $\mathrm{DiOC}_{6}(3)$ (Teresaki et al. 1986). Fluorescence produced by EROD activity and superoxide generation showed some apparent association with the ER but the distribution was often diffuse (Fig. 1C to F). Monochlorobimane reacts specifically with reduced glutathione (GSH) and, here, the fluorescence showed diffuse localization in the cytoplasm. Fluorescence for NBDcolcemid binding to the colcemid binding-site on microtubules tended to be distributed throughout the cytoplasm. Texas Red-albumin was localized in vesicles believed to be endosomes and possibly also some lysosomes.

In fix-killed cells, fluorescence following treatment with $\mathrm{DiOC}_{6}(3), \mathrm{R} 6$ and monochlorobimane was present but reduced, particularly for the latter. There was no fluorescent reaction following treatment with dihydrorhodamine 123, 7-ethoxyresorufin or NBD-colcemid

\section{Measurements on field samples}

The results are summarised in Fig. 2 and show significant increases in oxyradical generation, EROD activity and apparent ER-associated fluorescence at the more contaminated inshore stations (Fig. 2). Glutathione and microtubule associated fluorescence were essentially the same for all sites and data is not shown for reasons of brevity; however, endocytosis of Texas Red albumin was dramatically reduced in hepatocytes from fish sampled from Stns $3,5 \& 6$ as compared to Stn 7; Stn 9 fish cells also showed a reduction (Fig. 2). The results for reduced glutathione were unexpected as experimental exposure to contaminated sediment and field samples from the Elbe River showed significant decreases in comparison with controls and clean reference respectively (Moore \& Köhler unpubl.).

The various cellular parameters were tested for evidence of correlation with total measured PCB congeners in liver and representative PAH's (total content of phenanthrene, fluoranthrene, pyrene and benzo(a)pyrene) in the sediments (Cofino et al. 1992). The only significant direct correlations were found to be between PCB's and oxyradical production ( $r=0.887$. $\mathrm{p}<0.05, \mathrm{n}=5$ ) and PAH's and oxyradical production $(r=0.92, p<0.05, n=5)$.

Cellular parameters were also tested against each other as well as those measured on cells from the same fish by Lowe et al. (1992). These latter included lysosomal retention of neutral red and uptake of acridine orange. Significant direct correlations were found between ER fluorescence and oxyradical production, endocytosis and lysosomal uptake of neutral red, as well as endocytosis and lysosomal retention of neutral red (Table 1). There was a strong inverse correlation between oxyradical production and lysosomal uptake of acridine orange, as well as oxyradical production and endocytosis (Table 1). 

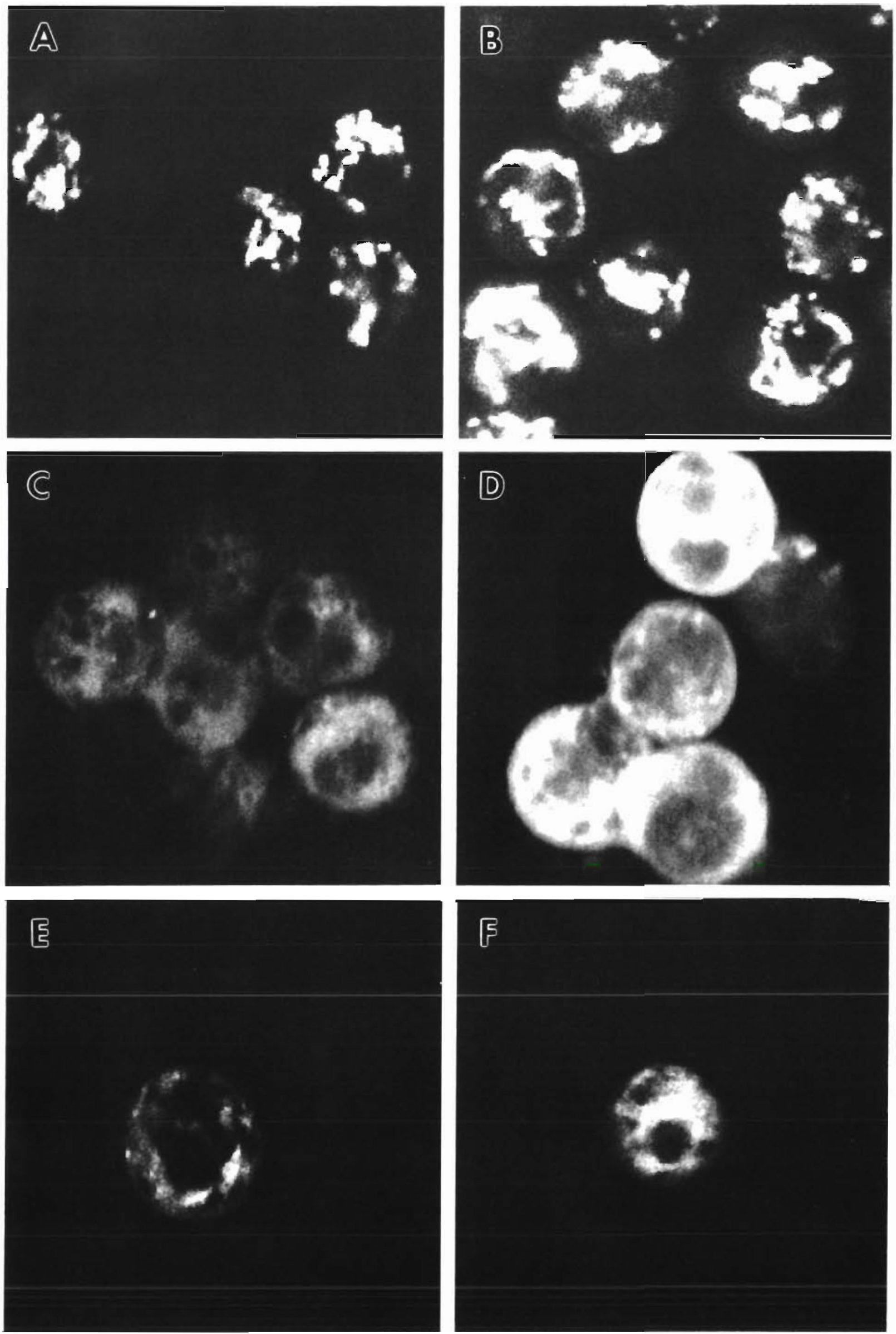

5 

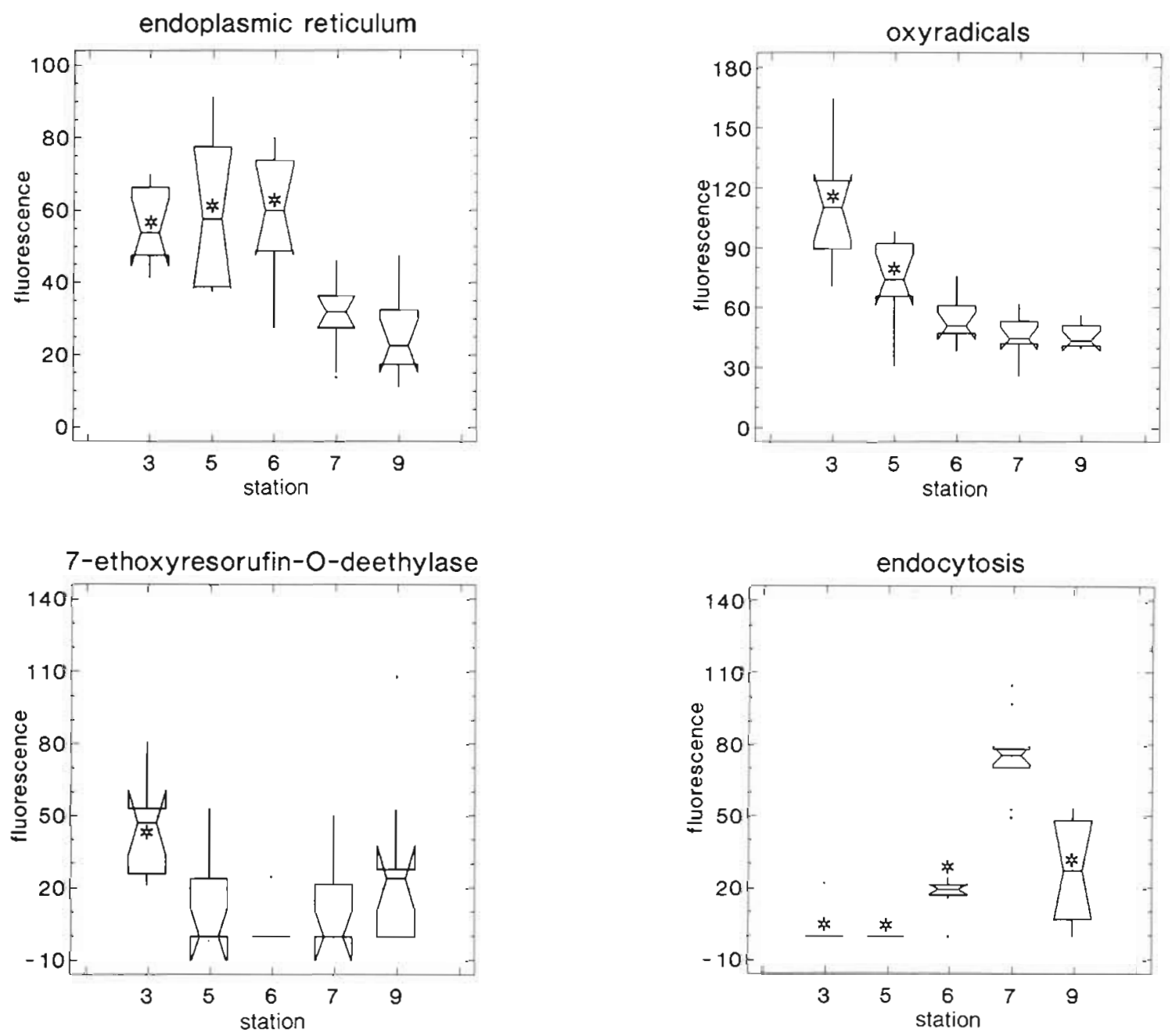

Fig. 2. Fluorescence intensity (arbitrary units) in isolated hepatocytes for ER (DiOC 6 [3]), EROD, oxyradicals and endocytosis. Results are represented by notched box and whisker plots; significant differences $(p<0.05)$ from the least contaminated Stn 7 are shown by asterisks. Data were assessed using the Mann-Whitney $U$-test ( $n=10$ fish per station with 20 measurements per fish)

\section{DISCUSSION}

These findings are consistent with the known effect of many lipophilic organic xenobiotics on the ER and biotransformation system (Stier 1978). The increase in ER-associated fluorescence with $\mathrm{DiOC}_{6}(3)$ indicates

Fig. 1. Limanda limanda. Laserscan confocal images of fluorescent molecular probes in live isolated hepatocytes. (A) $\mathrm{DiOC}_{6}(3)$ fluorescence in endoplasmic reticulum (ER) in hepatocytes from relatively uncontaminated fish. (B) Increased ER fluorescence in hepatocytes from contaminated fish. (C) EROD activity in hepatocytes as in (A). (D) Increased EROD activity in hepatocytes as in (B). (E) Fluorescence of rhodamine 123 due to oxyradicals in hepatocytes as in (A). (F) Increased fluorescence due to oxyradical production in hepatocytes as in (B). (All images $\times 2200$ ) proliferation of this system and the increase in cytochrome P-450 dependent EROD activity supports the evidence of a major effect on the ER-associated biotransformation apparatus (Stier 1978, Stegeman \& Lech 1991). The evidence for increased ER content is well supported by the ultrastructural findings of Köhler et al. (1992) on simultaneous samples from the same stations, which showed considerable ER proliferation in livers from fish caught at the inshore sites. A consequence of xenobiotic exposure is the oxidative stress imposed on animals as a result of one-electron metabolism giving rise to oxyradicals (Winston et al. 1991). Also, many organic xenobiotics can be metabolised to redox-cycling intermediates which proliferate the production of oxyradicals, particularly in the ER (Di Giulio et al. 1989). That this process may be occurring in the liver cells is supported by the correlational evidence 
Table 1. Correlational analyses between various intracellular parameters

\begin{tabular}{|c|c|c|}
\hline Cellular parameters ${ }^{d}$ & \multicolumn{2}{|c|}{$\begin{array}{l}\text { Rank correlation Probability } \\
\text { coefficient }{ }^{\mathrm{b}}\end{array}$} \\
\hline $\begin{array}{l}\text { Lysosomal uptake of acridine } \\
\text { orange/endocytosis }\end{array}$ & 0.71 & $\mathrm{p}<0.00005$ \\
\hline $\begin{array}{l}\text { Lysosomal retention of neutral } \\
\text { red/endocytosis }\end{array}$ & 0.76 & $p<0.00005$ \\
\hline $\begin{array}{l}\text { Lysosomal retention of } \\
\text { neutral red/lysosomal uptake } \\
\text { of acridine orange }\end{array}$ & 0.64 & $p<0.00005$ \\
\hline $\begin{array}{l}\text { Lysosomal uptake of acridine } \\
\text { orange/oxyradical production }\end{array}$ & -0.73 & $p<0.00005$ \\
\hline $\begin{array}{l}\text { Endocytosis/oxyradical } \\
\text { production }\end{array}$ & -0.67 & $p<0.00005$ \\
\hline $\begin{array}{l}\text { Oxyradical production/ER } \\
\text { fluorescence }\end{array}$ & 0.46 & $p=0.0015$ \\
\hline $\begin{array}{l}\text { "Data taken from this paper and } \\
\text { relate to the same fish samples } \\
\text { b Spearman Rank Correlation }\end{array}$ & $\begin{array}{l}\text { Lowe et al. } \\
\text { efficient, } n=\end{array}$ & $\begin{aligned} & (1992) ; \text { both } \\
= & 50\end{aligned}$ \\
\hline
\end{tabular}

between ER proliferation and oxyradical production (Table 1).

Oxyradicals are also believed to be a major factor in attacking intracellular components, which results in cell injury (Di Giulio et al. 1989). On the basis of the data presented here, there is a strong inverse correlation between oxyradical production and both lysosomal integrity (based on uptake of acridine orange; Lowe et al. 1992) and endocytosis. These findings support the hypothesis that xenobiotic exposure results in increased oxyradical production leading to cell injury. Further evidence of cell injury in the same fish is apparent from the parallel work of Lowe et al. (1992) on lysosomal damage and enlargement, as well as the overexpression of ras oncoprotein in cellular foci throughout the livers of all fish from Stn 3 (Moore \& Evans 1992).

The clear indication that endocytosis is impaired by xenobiotic exposure should be considered in the broader context of functional damage to the processes of vesicular trafficking in the liver rells. Lowe et al. (1992) have demonstrated a loss of membrane integrity in another important component of the vesicular transport system, namely, the lysosomal compartment, while atrophy of the trans-Golgi system occurs in experimentally exposed dab (Moore et al. 1991). These findings suggest that the major perturbation of the vesicular system is a consequence of a multi-target attack on its various cellular components. The ramifications for liver cell function are considerable as the vesicular system is responsible for import and export of many proteins (e.g. egg yolk protein), as well as their intracellular transport and appropriate targetting
(Pfeffer 1992). Disturbance of the various components of this important cellular system will undoubtedly have an adverse affect on the physiology of the liver.

The conclusion is that fish from Stns 3 \& 5 were both exposed to and impacted by organic xenobiotics which induced proliferation of ER and increases in EROD activity (Stn 3 only) and oxyradical production in the liver cells. Furthermore, the cells were injured in a manner which is comparable to xenobiotic and radical attack in mammalian cells and damage to the liver was of such an extent as to impair integrated function (Köhler et al. 1992, Lowe et al. 1992, Simpson \& Hutchinson 1992). The results obtained from the use of the fluorescent molecular probes described above indicate their potential in identifying early onset molecular and subcellular biomarkers of xenobiotic-induced cell injury in isolated liver cells. In particular, proliferation of ER, increased EROD and radical production indicate exposure to toxic organic xenobiotics, while impairment of endocytosis is a marker of their damaging effect.

The methods used in this study could be readily modified for use with a fluorescence microtitre reader in larger scale biomonitoring. This would permit the rapid screening of large numbers of samples, while microscopy would only be required for cell counts, testing of cell viability and to validate the localization of fluorescence.

Acknowledgements. Funded under contract to the UK Department of the Environment as part of its co-ordinated programme of research on the North Sea (PECD Ref.7/8/137). Assistance in the preparation of isolated hepatocytes by Barry Evans is gratefully acknowledged. I also thank Zeiss Oberkochen (Hamburg) for their very generous loan of an Axiomat fluorescence microscope and TV camera.

\section{LITERATURE CITED}

Cofino, W. P., Smedes, F., de Jong, S. A., Abarnou, A., Boon, J. P., Oostingh, I., Davies, I. M., Klungsøyr, J., Wilhelmsen, S., Law, R. J., Whinnett, J. A., Schmidt, D., Wilson, S. (1992). The chemistry programme Mar. Ecol. Prog. Ser. 91: $47-56$

De Basio, R., Bright, G. R., Ernst, L. A., Waggoner, A. S., Taylor, D. L. (1987). Five-parameter fluorescent imaging: wound healing of living Swiss 3T3 celis. J. Cell Biol. 105 : $1613-1622$

Di Guilio, R. T., Wasbburn, P. C., Wenning, R. J., Winston, G.W., Jewell, C. S. (1989). Biochemical responses in aquatic animals: a review of determinants of oxidative stress. Environ. Toxicol. Chem. 8: 1103-1123

Haugland, R. P. (1989). Organelle probes. In: Haugland, R. P. (ed.) Molecular probes - Handbook of fluorescent probes and research chemicals. Molecular Probes, Inc., Eugene, p. $125-127$

Hinton, D. E. Laurén, D. J. (1990). Liver structural alterations accompanying chronic toxicity in fishes: potential biomarkers of exposure. In: McCarthy, J. F., Shugart, L. R. (eds.) Biomarkers of environmental contamination. Lewis Publishers, Boca Raton, p. 17-57 
Hiratsuka, T., Kato, T. (1987). A fluorescent analog of colcemid, N-(7-nitrobenz-2-oxa-1,3-diazol-4yl)-colcemid, as a probe for the colcemid-binding sites of tubulin and microtubules. J. biol. Chem. 262: 6318-6322

Köhler, A., Deisemann, H., Lauritzen, B. (1992). Histological and cytochemical indices of toxic injury in the liver of dab Limanda limanda. Mar. Ecol. Prog. Ser. 91: 141-153

Lohse, J. (1990). Distribution of organochlorine pollutants in North Sea sediments. In: Kruize, R. R. (ed.) North Sea pollution - Technical strategies for improvement. Wat. Sci. Tech. 24: 107-113

Lowe, D. M., Moore, M. N., Evans, B. M. (1992). Contaminant impact on interactions of molecular probes with lysosomes in living hepatocytes from dab Limanda limanda. Mar. Ecol. Prog. Ser. 91: 135-140

Moore, M. N. (1990). Lysosomal cytochemistry in marine environmental monitoring. Histochem. J. 22: 187-191

Moore, M. N., Evans, B. (1992). Detection of ras oncoprotein in liver cells of flatfish (dab) from a contaminated site in the North Sea. Mar. environ. Res. 34: 33-38

Moore, M. N., Simpson, M. G. (1992). Molecular and cellular pathology in environmental impact assessment. Aquat. Toxicol. 22: 313-322

Moore, M. N., Lowe, D. M., Bucke, D., Dixon, P. (1991). Molecular and cellular markers of pollutant exposure and liver damage in fish. ICES, C.M. 1991/E:23

Pfeffer, S. R. (1992). GTP-binding proteins in intracellular transport. Trends Cell Biol. 2: 41-46

Rice, G. C., Bump, E. A., Shrieve, D. C., Lee, W., Kovacs, M. (1986). Quantitative anlaysis of cellular glutathione by flow cytometry utilizing monochlorobimane: some applications to radiation and drug resistance in vitro and in vivo. Cancer Res. 46: 6105-6110

Rijnsdorp, A. D., Vethaak, A. D., van Leeuwen, P. I. (1992).
Population biology of dab Limanda limanda in the southeastern North Sea. Mar. Ecol. Prog. Ser. 91: 19-35

Simpson, M. G., Hutchinson, T H. (1992). Toxicological pathology of dab Limanda limanda along pollution gradients in the southern North Sea. Mar Ecol. Prog. Ser 91 $155-161$

Spies, R. B., Rice, D. W., Felton, J. (1988). Effects of organic contaminants on reproduction of the starry flounder (Platichthys stellatus) in San Francisco Bay. I. Hepatic contamination and mixed-function oxidase (MFO) activity during the reproductive season. Mar. Biol. 98: 181-189

Stegeman, J. J., Lech, J. J. (1991). Cytochrome P-450 monooxygenase systems in aquatic species: carcinogen metabolism and biomarkers for carcinogen and pollutant exposure. Environ. Health Perspect. 90: 93-100

Stier, A. (1978). Membrane fluidity. In: Slater, T. F. (ed.) Biochemical mechanisms of liver injury. Academic Press, London, New York, p. 219-336

Teresaki, M., Chen, L. B., Fujiwara, K. (1986). Microtubules and the endoplasmic reticulum are highly interdependant structures. J. Cell Biol. 103: 1557-1568

Teresaki, M., Song, J. D., Wong, J. R., Weiss, M. J., Chen, L. B. (1984). Localization of endoplasmic reticulum in living and glutaraldehyde fixed cells with fluorescent dyes. Cell 38 : 101-108

White, I. N. H. (1988). A continuous fluorometric assay for cytochrome P-450 dependant mixed function oxidases using 3-cyano-7-ethoxycoumarin. Anal. Biochem. 172: $304-310$

Winston, G. W., Moore, M. N., Straatsburg, I., Kirchin, M. (1991). Decreased stability of digestive gland lysosomes from the common mussel Mytilus edulis L. by in vitro generation of oxygen-free radicals. Arch. environ. Contam. Toxicol. 21: 401-408 